\title{
A Educação Científica das Periferias Urbanas: Uma Revisão sobre o Ensino de Ciências em Contextos de Vulnerabilidade Social (1985-2018)
}

\section{Science Education in Urban Peripheries: A Review of Science Teaching in Contexts of Social Vulnerability (1985-2018)}

\author{
Sullyvan Garcia-Silva \\ Brasil \\ Paulo Lima Junior \\ Brasil
}

O objetivo central deste trabalho é apresentar uma revisão internacional e nacional de artigos sobre a educação científica das periferias urbanas. Tomando como ponto de partida duas revisões que cobrem o período de 1985 a 2013, nós as expandimos até o ano de 2018 buscando por artigos publicados nos periódicos nacionais e internacionais de mais alto impacto. Como resultado, percebemos que a literatura recente (2014-2018) pode ser agrupada em três grandes perspectivas coexistentes (tradicional, crítica e póscrítica) descritas por 11 temas de investigação. Ao mesmo tempo em que perspectivas contemporâneas emergem vigorosamente na literatura, as perspectivas tradicionais, inspiradas pela racionalidade técnica e pelo eficientismo, não foram jamais superadas. A análise também permitiu conjecturar a baixa ocorrência de artigos sobre educação científica das periferias urbanas em periódicos brasileiros. Implicações para a educação científica são discutidas.

Palavras-chave: Educação científica das periferias urbanas; Classe popular; Cor, Raça e Racismo; Minorias.

The main objective of this work is to present an international and national review of articles on scientific education in urban peripheries. Taking as a starting point two revisions covering the period from 1985 to 2013, we expanded them until the year 2018, looking for articles published in national and international journals with the highest impact factor. As a result, we realized that recent literature (2014-2018) can be grouped into three major coexisting perspectives (traditional, critical and post-critical), described by 11 research topics. At the same time that contemporary perspectives emerge vigorously in the literature, traditional perspectives, inspired by technical rationality and efficiency, have never become outdated. The analysis also made it possible to conjecture the low occurrence of articles on scientific education in urban peripheries in Brazilian journals. We then discuss implications for science education.

Keywords: Urban science education; Popular class; Color, Race and Racism; Minorities. 


\section{Introdução}

Há algumas décadas, a pesquisa em educação científica tem se tornado progressivamente mais consciente da necessidade de situar o ensino de ciências no contexto dos problemas e contradições sociais de nosso tempo, pressionando as fronteiras estabelecidas pela racionalidade técnica e pelo entendimento de que a aquisição de conhecimento é o único e principal objetivo do ensino de ciências. Nesse sentido, o espectro de problemas sociais abordados pela literatura é bastante amplo, podendo compreender questões de classe (Maulucci, Brown, Grey, \& Sullivan, 2014), gênero (Kwah, Milne, Tsai, Goldman, \& Plass, 2014), cor (Chapman, \& Feldman, 2016; Ball, 2017) e religião (de Carvalho, 2016). Conforme esperado, o olhar da comunidade sobre esses temas está se adaptando constantemente às formas que a exclusão assume em cada tempo histórico, em cada lugar.

No contexto dos problemas educacionais mais atuais, a militarização de algumas escolas públicas coloca em pauta a questão da violência urbana, da vulnerabilidade social, da vida das periferias das cidades brasileiras com todos os seus desdobramentos para o ensino (de ciências). Resposta para a garantia da segurança e controle disciplinar nas escolas periféricas, a militarização tem sido defendida pelas personalidades mais conservadoras do campo político e, ao mesmo tempo, tem ganhado o apoio de pais e professores que não veem outra saída para contornar a dificuldade que a escola tem encontrado de impor legitimamente sua autoridade pedagógica (Belle, 2011).

Este artigo faz parte de uma pesquisa mais ampla que investiga os desafios enfrentados, as práticas de ensino e o desenvolvimento profissional de professores de ciências das periferias urbanas. Portanto, este texto busca fornecer elementos teóricos para professores de ciências de todas as redes de ensino no país, formadores de professores e pesquisadores que procuram compreender a temática da educação científica das periferias urbanas no Brasil e parte do exterior. Aqui é apresentada uma revisão da literatura sobre o ensino de ciências nos contextos menos privilegiados das grandes cidades. Tomamos como ponto de partida as revisões anglófonas realizadas por Barton (2002) e McLaughlin (2014), que, juntas, abrangem o período de 1985 a 2013. Essas revisões foram retomadas e expandidas com artigos de 2014 a 2018 publicados em periódicos no Brasil ou no exterior. Na primeira seção, retornamos à revisão da literatura de Barton (2002) que, cobrindo o período de 1985 a 2000, reporta a emergência da educação científica das periferias urbanas. Em seguida, são apresentados os 03 elementos teóricos (linguagem, identidade e reforma) discutidos na revisão de McLaughlin (2014), no qual abrange o período de 2000 a 2013. Na próxima seção é trabalhado os conceitos de Educação científica tradicional, crítica e pós-critica das periferias urbanas. As duas seções posteriores trabalham em conjunto com a seleção das fichas de leitura. Na primeira parte são apresentados os procedimentos metodológicos realizados para a escolha dos artigos (2014-2018) e na segunda, os conceitos e contextos relativos ao olhar que a educação científica possui das periferias urbanas. Por último são apresentados os resultados desses 50 artigos selecionados classificados em 11 temas emergentes. 


\section{A emergência da "urban science education" (1985-2000)}

Ângela Calabrese Barton publicou em 2002, na revista inglesa Studies in Science Education, uma importante revisão de literatura sobre a "educação científica urbana" (ing. urban science education). O texto é um marco sobre a temática, pois conseguiu reunir diversas análises sobre a educação científica no contexto das periferias urbanas.

Mas o que é necessário para que um estudo faça parte da urban science education? Qual é o sentido dado ao "urbano" nestes estudos? Como primeira aproximação, o termo "urbano" empregado designa especificamente as regiões mais violentas e vulneráveis das grandes cidades, com maior presença de minorias sociais (e.g. negros e migrantes), onde as condições de vida são relativamente mais precárias. Essas regiões podem não ser fisicamente periféricas (podem não estar na borda da cidade), mas são periféricas do ponto de vista da falta de garantias e acesso de oportunidades em usufruir direitos adquiridos. Em muitas metrópoles, as regiões mais vulneráveis estão nos centros depredados, em prédios abandonados próximos às estações rodoviárias, onde a circulação de pessoas é muito maior e os mais abastados não conseguem se distinguir. De fato, essas regiões mais vulneráveis (ditas urbanas) são nomeadas em oposição às regiões suburbanas típicas da América do Norte, onde as famílias privilegiadas conseguem se estabelecer confortavelmente nas casas amplas e seguras dos bairros mais afastados. Assim, por analogia, e respeitando que cada cidade tem uma construção singular que não se transporta imediatamente de um contexto a outro, encontramos na expressão "educação das periferias urbanas" a melhor tradução para urban education. Vale a ressalva de que não estamos falando aqui de uma periferia física (perímetro da cidade), mas uma periferia social - que assume formas e lugares específicos em cada cidade, mas que sempre será interpretada como um espaço de exclusão.

A pesquisa sobre a educação científica das periferias urbanas tem, em geral, preocupações com as origens, o desenvolvimento e natureza das cidades, a relação entre as pessoas e os ambientes construídos, economia urbana, governo e políticas públicas, e processos que moldam os bairros da cidade ao longo do tempo, incluindo os centros urbanos, pequenos distritos dentro dos limites do município e cidades periféricas, assim como também aspectos históricos, físicos, ambientais, sociais, econômicos e políticos (Barton, 2002). Portanto, a educação das periferias urbanas traz um olhar crítico para lugares, pessoas, estruturas e culturas quase sempre esquecidas pelos detentores do poder.

Para que um estudo faça parte da educação científica das periferias urbanas, Barton (2002) sugere ser necessário atender aos seguintes critérios:

(1) que o contexto de investigação seja especificamente periférico [urban] e nomeado como tal, (2) que as questões e métodos de pesquisa que orientam o trabalho levem em consideração contexto periférico como parte central da investigação, e (3) que a análise e as asserções de conhecimento feitas reflitam uma intenção de gerar conhecimento especializado baseado na educação científica 
das periferias urbanas (Barton, 2002, p. 04, nossa tradução).

O objetivo destes critérios é tornar a pesquisa sobre a educação científica das periferias urbanas particularmente relevante, eliminando estudos que, mesmo ocorrendo em cenários periféricos, não refletem realmente sobre as particularidades desses contextos. Na revisão seguinte (McLaughlin, 2014) e na nossa própria revisão, esses critérios são preservados para decidir quais artigos serão efetivamente revisados e quais serão considerados ocorrências casuais dos termos empregados no mecanismo de busca.

Partindo de um corpus final de 46 artigos selecionados pelos buscadores ERIC, First Search e Ingenta, após examinar as principais revistas (e.g. Science Education, Journal of Research in Science Teaching, Research in Science Education, and the International Journal of Science Education), Barton (2002) sintetizou a pesquisa sobre educação científica das periferias urbanas em três temas transversais:

(a) Uma questão de condições: um compromisso com a equidade,

(b) Uma questão de orientação: um compromisso com a justiça social,

(c) Uma questão de contexto: um compromisso com um senso de lugar.

A equidade não é um conceito novo para educadores de ciências. Ao longo do século passado várias insurgências aconteceram em busca pela equidade. Barton (2002) cita, como exemplo, o movimento de mulheres nas nações ocidentais na década de 60 que buscavam respostas pela falta de acesso e oportunidade nas carreiras científicas. Mais tarde, nos anos 80, pesquisadores em educação científica e formadores de políticas públicas de muitos países ocidentais comprometeram-se com a "ciência para todos" e não apenas "para cientistas" (Stuckey, Hofstein, Mamlok-Naaman, \& Eilks, 2013).

Essa mudança no objetivo de ensinar ciências tornou-se importante porque, em uma sociedade que avançava a passos largos tecnologicamente, as pessoas precisavam aprender e ser capazes de lidar com estes novos contextos. Portanto, o lema "ciência para todos" tentava trazer democracia onde havia apenas disposições elitistas. Neste contexto, também pressionados pelo lançamento de Sputnik pelos soviéticos e pela necessidade de formar mais cientistas, ensinar ciências num ambiente de vulnerabilidade tornou-se um desafio para todos os envolvidos na educação. Assim, democratizar recursos materiais, humanos e sociais era um dos caminhos a serem percorridos para buscar a reduzir as distâncias do ensino praticado entre periferia e centro.

O segundo valor apresentado por Barton (2002) nos estudos da educação científica das periferias urbanas é o compromisso com a justiça social. Uma perspectiva encontrada em sua revisão foi o esforço em documentar como sistema de ensino, escola, professores, agentes e estudantes contribuem para perpetuar as forças econômicas, sociais e políticas que moldam a vida nas escolas urbanas (Barton, 2002). Outra perspectiva destacada é da justiça social como luta coletiva para transformar a realidade das escolas. A luta, de fato, provoca um ambiente de interação, de conhecimento e de envolvimento 
de professores e alunos em críticas que poderão transformar o espaço escolar em práticas para a ciência (Barton, 2002).

Por último, Barton (2002) apresenta o senso de lugar, destacando que grande parte dos estudos em educação científica das periferias urbanas se concentram no acesso, recursos, povos e culturas, mas deixam um pouco de lado o papel que a geografia física possui nos ambientes urbanos, demarcando de forma muito visível, o que é periférico e o que não é (Barton, 2002). Ela argumenta que o senso de lugar é "crucial para entender como os indivíduos se relacionam uns com os outros e com as estruturas que governam suas vidas" (Barton, 2002, p. 24, tradução nossa).

\section{Linguagem, identidade e reforma (2000-2013)}

Cheryl A. McLaughlin (2014) continuou o trabalho feito por Barton (2002) e apresentou uma revisão de literatura que abrangeu o período de 2000 a 2013, exclusivamente no contexto norte americano, com a seleção de 42 artigos entre 68 trabalhos obtidos na base de dados (ERIC, PyschInfo, Web of Science e JSTOR). Nesta seleção ela agrupou os trabalhos em três outros temas:

(a) Barreiras ao ensino e aprendizagem em sala de aula;

(b) Posicionalidade e construção da identidade; e

(c) Estratégias de reforma.

Primeiramente, McLaughlin (2014) apresenta as barreiras ao ensino e aprendizagem em sala de aula como as diferenças culturais e linguísticas existentes das periferias descritas nos artigos pesquisados. McLaughlin (2014) apresenta a visão de alguns educadores americanos que acreditavam que os imigrantes deveriam ser "aculturados" para melhor se adequarem ao sistema de ensino norte-americano, obedecendo às normas dominantes americanas como forma de ajustamento aos pensamentos e padrões pré-estabelecidos. Outro ponto importante destacado por McLaughlin (2014) foi que as crianças imigrantes tiveram que evitar sua própria cultura e adotar a linguagem e os costumes do novo país, dessa forma, conflitos culturais e linguísticos eram comuns e contribuíam para o baixo nível acadêmico.

Quanto à posicionalidade e construção da identidade, McLaughlin (2014) nos mostra que a educação científica abordada em sua revisão de literatura compreende a ideia de que os estudantes deveriam assumir um papel mais ativo numa educação transformadora, criando seus próprios significados por meio da reflexão crítica. Mas, para que isso aconteça, professores deveriam promover a construção de identidade de seus alunos, observando as práticas sociais e culturais dentro da escola, para, enfim, saber usar uma estratégia que contemple este objetivo (Mclaughlin, 2014).

A identidade é uma construção social continuamente moldada pelas práticas discursivas e talvez seja, segundo McLaughlin (2014), o meio mais poderoso pelo qual os alunos interpretam suas experiências individuais, que é fundamental para nossa discussão 
sobre os estudantes periféricos e seu (não) pertencimento à cultura dominante da ciência. Para McLaughlin (2014), as identidades assumidas pelos estudantes são resultado das associações e interações cotidianas envolvendo poder, afiliações e privilégios relativos existentes dentro das estruturas de relações sociais da vida cotidiana, que moldam suas posições dentro de suas salas de ciências e da sociedade em geral.

A posicionalidade é um construto usado para descrever a posição simbólica que um indivíduo é designado ou assume com base em suas representações sociais e culturais em um determinado ambiente. Conforme McLaughlin (2014) essas posições são geralmente associadas a gênero, classe, orientação sexual e cor. É importante destacar que uma sala de aula é um microuniverso da sociedade e distinções entre posições sociais ocorrem na medida em que os alunos procuram entender seu espaço dentro dessa esfera social. A posicionalidade é, portanto, fundamental para a nossa compreensão de como os alunos constroem suas identidades enquanto dão sentido às culturas e discursos científicos dominantes (McLaughlin, 2014). Outro ponto que vale a pena discutir é quando estudantes são pressionados a abandonar suas identidades em favor da ciência. Em uma escola de periferia, como foi discutido, nem sempre são proporcionadas as experiências necessárias para que os estudantes consigam se identificar como praticantes legítimos de ciências. Nesses casos, a (não) identificação com a ciência pode funcionar como parte de um processo de enculturação a serviço da cultura dominante.

Por último, McLaughlin (2014) aborda as estratégias de reformas como terceiro grande tema da educação científica das periferias urbanas entre 2000 e 2013 . Nele, ela aponta que um tema central para as reformas no ensino de ciências, priorizando as escolas com vulnerabilidade social, é a criação de ambientes de aprendizagem que permitem que todos os alunos, independente de raça, cultura, gênero e status socioeconômico, adquiram atitudes positivas em relação à cultura da ciência e desenvolvam sua identidade. É importante destacar que o contexto utilizado por McLaughlin (2014) em sua revisão de literatura é o norte americano. Portanto, é necessário entender as aproximações (em geral as populações em vulnerabilidade social, são negras e pobres) e distanciamentos (nos Estados Unidos existe um contexto de xenofobia em relação a população latina que não é igualmente encontrada aqui no Brasil) entre esse contexto e o brasileiro. Nos Estados Unidos, as reformas são usualmente implementadas por grupos mais poderosos que costumam estar comprometidos com a manutenção das relações de força que os colocaram onde estão. Com efeito, ainda que o discurso político possa assumir formas variadas (ou opostas), muitas reformas não fazem mais que gerar transformações capazes de manter uma hierarquia social pré-existente (para prejuízo das periferias). Alguns atores políticos podem, por exemplo, argumentar que não há a necessidade de educar uma criança que vive na periferia como são educados os filhos das famílias mais privilegiadas. Outros defenderão a neutralidade e igualdade das avaliações como marca da legítima meritocracia, quando, em realidade, os filhos da periferia não concorrem em igualdade de condições. Em todo caso, é saudável lembrar que o sistema de relações que produz e reproduz as relações periferia-centro não é exclusivamente escolar e, portanto, 
não pode ser completamente superado a partir de uma reforma restrita ao espaço escolar.

\section{Educação científica tradicional, crítica e pós-crítica das periferias urbanas}

As revisões de Barton (2002) e McLaughlin (2014) apontam compromissos gerais que, de forma mais ou menos indisputada, orientam (ou deveriam orientar) a pesquisa em educação científica das periferias urbanas. No entanto, outra forma (talvez mais interessante) de revisar a literatura consiste em buscar os dissensos, as discordâncias que permitem representar a pesquisa como um espaço de disputas e oposições. De fato, quando olhamos a passagem de uma revisão à outra, percebemos a emergência de temas novos - ou a transformação de temas conhecidos.

Considere, por exemplo, a questão da equidade. Na revisão de Barton (2002) ela aparece inicialmente ligada à carência de recursos didáticos e humanos. Em outras palavras, as escolas de periferia são representadas como espaços de escassez objetiva. $\mathrm{Na}$ revisão de McLaughlin (2014), a falta de igualdade está mais relacionada à linguagem, à posição social, à identidade. Sem negar a escassez objetiva das escolas de periferia (local, cuja infraestrutura e as condições de trabalho são geralmente mais precárias), os estudos recentes da identidade científica tendem a apresentar o universo dos estudantes de periferia como repleto de uma riqueza discursivamente marginalizada, recusada. Assim, a educação científica das periferias urbanas congrega perspectivas que se articulam sem concordar. Em última análise, não se trata de um espaço de consensos. Tendo isso em mente, é até possível perceber que estudos mais tradicionais - tais como os que apostam em soluções técnicas e tecnológicas para os desafios da periferia -, apesar de serem muito frequentes na pesquisa em educação científica como um todo, foram desconsiderados nas duas revisões.

Com o objetivo de sublinhar os desacordos em torno dos quais a pesquisa em educação das periferias urbanas está organizada, tomamos emprestadas três categorias meta-teóricas da teoria do currículo (Silva, 2009) e propomos classificar os artigos de nossa revisão nesses três grandes grupos:

(a) Educação Tradicional das periferias urbanas;

(b) Educação Crítica das periferias urbanas;

(c) Educação Pós-Crítica das periferias urbanas.

Inicialmente, todos os artigos foram submetidos a uma análise categorial temática (Bardin, 1977), classificados em relação ao tema dos resultados reportados. Essa classificação resultou em 11 categorias (descritas posteriormente) que, por sua vez, são prolongamentos das três macrocategorias acima.

Desta forma, identificamos a Educação Tradicional das periferias urbanas em todas as abordagens que pretendem tornar os processos de ensino mais eficientes (do ponto de vista da aquisição de conhecimento e de atitudes favoráveis à ciência), por meio da inovação técnica e tecnológica, deixando em segundo plano as desigualdades 
sociais que caracterizam a periferia. Nessa abordagem, são importantes: o ensino, enquanto processo, e a aprendizagem, enquanto produto; a avaliação, enquanto método padronizado de aferição de resultados; a inovação técnica como ferramenta de otimização (i.e., permitindo atingir os mesmos objetivos educacionais com economia de recursos); a organização, o planejamento e a eficiência da gestão (Silva, 2009). Do ponto de vista tradicional, o currículo é apresentado como se fosse neutro, dissimulando os interesses políticos que o produziram.

Do ponto de vista das teorias do currículo (Silva, 2009), as abordagens tradicionais surgem na década de 1920, nos Estados Unidos, e jamais abandonaram completamente o discurso educacional. Sua emergência está relacionada ao fortalecimento da sociedade industrial e à demanda de massificar a escolarização de americanos e imigrantes. São exemplos de autores influentes dessa tradição de pensamento: Bobbitt (2004) e Tyler (1983). A referência a esses autores, no entanto, é rara e não foi utilizada para classificar os artigos de nossa revisão. Tudo indica que o pensamento tradicional se perpetua na educação científica das periferias urbanas como uma repetição discursiva irrefletida.

A Educação Crítica, por sua vez, surge na década de 1970, quando as economias liberais capitalistas se mostravam esgotadas em face da dificuldade de manter a remuneração do capital nos mesmos patamares históricos, aprofundando as desigualdades sociais, a pobreza e a injustiça. O sistema escolar, que vinha se expandindo desde a declaração universal dos direitos humanos em 1948, não estava proporcionando as mesmas oportunidades a todos. Foi também nesse período que o neoliberalismo se instalou em algumas das principais economias do mundo. Como resposta a essa crise, autores como Henry Giroux (2001) e Michael Apple (1982), desde o programa de pesquisa marxista, denunciam o sistema educacional liberal como controlador da sociedade, reproduzindo e aumentando as desigualdades e injustiças sociais. Pierre Bourdieu e Jean-Claude Passeron (2016), Louis Althusser (2013), Basil Bernstein (1996), e Paulo Freire (2008) também têm seus trabalhos seminais publicados na mesma época. A partir daí, é pensado um currículo crítico que, se não foi plenamente capaz de promover a resistência e a transformação social, foi bem-sucedido em explicitar o papel da escola tradicional na reprodução das desigualdades.

Guardadas as particularidades de cada autor, o tema principal dessa geração de pensadores pode ser situado na relação entre dois sistemas de relações: o sistema de classes, por um lado, e o sistema escolar, por outro. Por referência direta ou indireta às suas obras, a contribuição desses autores pode ser percebida mais claramente na pesquisa em educação científica das periferias urbanas quando são tratadas questões de classe e de justiça social - tal como a escassez dos recursos escolares (equipamentos, laboratórios, pessoal qualificado) nas escolas periféricas. Em síntese, identificamos a abordagem crítica por manter, ora uma posição contundente sobre o papel reprodutor da escola tradicional, ora uma posição transformadora e libertadora.

Entendemos por Educação Pós-Crítica um conjunto ainda mais diversificado de perspectivas educacionais que têm em comum se opor a autores que já eram críticos 
da educação tradicional. São temas recorrentes dessa terceira geração as questões de identidade, diferença, subjetividade, poder, linguagem. Em oposição à noção de classe, que, em nome da qual costumam ser realizadas algumas generalizações sobre diferentes formas individuais de ser e agir, diversos autores pós-críticos trabalham pelo resgate da individualidade sem que isso signifique retornar ao pensamento liberal. O saber e o poder continuam sendo questões importantes para a educação pós-crítica, assim como eram para os autores da educação crítica. Contudo, aqui, esse saber/poder é descentralizado, não pertence mais ao Estado ou à Classe, mas está presente em toda a malha social. Portanto, a educação pós-crítica avança na medida em que ultrapassa a crítica das relações econômicas e dos imperativos de justiça, percebendo o poder como uma rede de relações (Silva, 2009). Entre as influências sobre esse conjunto muito heterogêneo de perspectivas educacionais, podemos citar: Michel Foucault (2002), Judith Butler (2003), Jaques Derrida (2009), Gilles Deleuze (1992), Zygmunt Bauman (2001), Ulrich Beck (2010).

É claro que essa distinção teórica de três grandes ondas educacionais (tradicional, crítica e pós-crítica) tem limitações tremendas. Muito simplificadora, ela agrupa na mesma família perspectivas que dificilmente reconhecerão uma à outra como semelhantes. A ideia de sucessão em torno da qual essas perspectivas são didaticamente apresentadas (cf. Silva, 2009) também pode criar uma ilusão de substituição, evocando tacitamente a ideia iluminista de progresso segundo a qual é sempre possível organizar o conhecimento em uma linha de desenvolvimento onde as etapas posteriores levam vantagem clara sobre as anteriores. Esse tipo de apresentação do pensamento educacional contemporâneo precisa ser tratado com muita desconfiança. As questões de classe (mais atrasadas na escala triunfalista da pós-crítica), não deixam de existir quando paramos de tratar delas. Invisíveis, são ainda mais poderosas.

Cientes de todos esses limites, por que nos demos o trabalho de empregar essa classificação? Apesar de sua simplicidade, as abordagens tradicional, crítica e póscrítica permitirão abordar a educação científica das periferias como um espaço de disputas, dissenso, contendas - em oposição a uma espaço construído em torno de valores consensualmente compartilhados, tal como Barton (2002) e McLaughlin (2014) sugerem.

Como já vimos, as revisões de Barton (2002) e McLaughlin (2014) parecem respectivamente inspiradas por teorias críticas e pós-críticas. Ao mesmo tempo, nenhuma das duas dá voz às teorias tradicionais em suas revisões. Porém, para esta revisão, foi importante retomar estas 03 (três) categorias, pois todas estão presentes nos artigos lidos e que serão apresentados na próxima seção. A saber, não foi encontrado nenhum artigo que se localizasse apenas uma linha teórica, seja ela tradicional, crítica ou pós-crítica. Mais tarde discutiremos como esse problema de ambiguidade da codificação foi contornado. 


\section{O debate em sua atualidade (2014-2018): Seleção dos artigos e preparação das fichas de leitura}

Para expandir e atualizar essas revisões da literatura, foram utilizados procedimentos semelhantes aos estabelecidos por Barton (2002) e McLaughlin (2014) para encontrar artigos sobre educação científica das periferias urbanas em língua inglesa e portuguesa. Para os artigos em língua inglesa, buscamos por trabalhos com publicação entre 2014 e 2018 em periódicos de relevância internacional escolhidos segundo seus parâmetros de impacto no ano de 2016: Science Education (SE), Journal of Research in Science Teaching (JRST); Journal of Science Education and Technology (JSET) e Cultural Studies of Science Education (CSSE). A Revista CSSE não possuía parâmetro de impacto, mas foi acrescentada devido à sua relevância para o tema desta revisão.

As palavras-chave utilizadas na ferramenta de busca da Scopus foram: urban; peripheral e poverty. O uso da palavra "urban" no buscador cobre a ocorrência dos termos "urban education", "urban science" e "urban science education", cujo sentido já foi introduzido aqui. Dessa maneira, 55 artigos de língua inglesa foram encontrados. Esses artigos foram submetidos a uma seleção manual, buscando identificar quais efetivamente tratavam da educação científica das periferias urbanas, eliminando os artigos que apresentavam as palavras-chave em sentido outro ao delimitado por Barton (2002). Após essa seleção, 47 artigos foram mantidos na revisão.

Para a busca de artigos em língua portuguesa, utilizamos os critérios mais próximos possíveis. O SciElo foi escolhido como indexador, pois, segundo o documento de área disponível à época, todos os periódicos latino-americanos classificados no primeiro estrato do Qualis (A1 e A2) ensino seriam encontrados ali. Foram inseridos os radicais das palavras urbano, periferia e pobreza (de maneira a buscar flexões de gênero, número e derivações desses vocábulos), mas a ocorrência de "educação científica" ou "ensino de ciências" foi exigida. Não foi imposta nenhuma restrição de tempo, cobrindo todo o período de 1985 a 2018 ou até o limite da disponibilidade dos artigos na base de dados. Dessa maneira, foram encontradas 23 ocorrências. Esses artigos também foram submetidos a uma seleção manual segundo os critérios de pertinência propostos por Barton (2002). Após essa seleção, somente 03 artigos foram selecionados para revisão, totalizando 50 artigos entre publicações internacionais e nacionais. A baixa ocorrência de artigos brasileiros será discutida ao longo da revisão, mas ela já antecipa que, enquanto a educação científica das periferias urbanas é um tema que mobiliza a comunidade anglófona há algumas décadas, o tema da educação das periferias parece não ter chegado de forma igualmente consistente ao ensino de ciências no Brasil.

Feita a seleção dos artigos, eles foram analisados e fichados segundo seu conteúdo. As fichas foram elaboradas com o propósito de responder às seguintes questões de pesquisa:

(a) Em que sentidos a educação científica das periferias é empregada?

(b) Qual o contexto das pesquisas apresentas na Educação Urbana em Ciências? 
(c) Qual os resultados e implicações dos artigos selecionados?

Essas perguntas organizam nossa apresentação da revisão. Posteriormente, elaboramos categorias que agrupam as perspectivas sobre a educação científica das periferias urbanas.

\section{Sentidos emprestados à educação científica das periferias urbanas}

Como primeira aproximação, urban science education pode ser traduzida como educação científica das periferias - nos termos indicados aqui. Porém, mesmo em português, a definição dos termos não esgota a variedade dos sentidos emprestados à mesma expressão. Afinal, de que periferia e de que educação científica estamos falando?

Inicialmente, percebemos que a maioria dos autores não delineia com clareza o que eles entendem por educação científica das periferias. Porém, 13 dos artigos revisados evocam compromissos éticos mais ou menos específicos por meio dos quais explicitam seu olhar sobre as comunidades de periferia e sua educação científica. Tais artigos podem ser agrupados em torno de quatro tendências:

1. Para alguns, a necessidade de justiça social é a principal definidora da educação científica das periferias urbanas (e.g. Davis, Ingber, \& McLaughlin, 2014; Maulucci et al., 2014; Mclaughlin, 2014; Brkich, 2014; Duran, Höft, Lawson, Medjahed, \& Orady, 2014; Zhang, Barnett, Wassell, Kate, Tan, \& Calabrese, 2016; Morales-Doyle, 2017; Ganhor, 2019). Eles argumentam que é preciso dar atenção especial às condições sociais e econômicas aos estudantes, especialmente negros e de baixa renda.

2. Para os autores que argumentam a participação democrática como compromisso fundamental da educação científica das periferias urbanas (Tolbert, \& Bazzul, 2016), é preciso proporcionar, no ensino de ciências, espaços de contestação favoráveis ao engajamento político das comunidades.

3. Outros autores estão mais concentrados na relação entre currículo $e$ desempenho (Varelas, Pieper, Arsenault, Pappas, \& Keblawe-Shamah, 2014; Chapman, \& Feldman, 2016), apontando que a memorização de conteúdos afeta diretamente o desempenho em avaliações, prejudicando a autoestima dos estudantes e reforçando a imagem da periferia como um espaço de carência.

4. Outros trabalhos têm a construção de uma identidade investigativa como elemento central da educação científica das periferias (Soares, Silva, \& Cavalheiro, 2001; Shady, 2014; McLaughlin, 2014; Schindel Dimick, 2016), onde os sentidos se dão pela continuidade do "fazer" ciências moldados pelas práticas discursivas, nos quais, os alunos interpretam suas experiências individuais de acordo com o espaço vivido e a representação da cultura dominante da ciência. 


\section{O que qualifica uma periferia urbana?}

A posição periférica, por construção, é sempre relativa. Embora cada analista possa herdar uma noção mais ou menos adequada das populações e dos lugares periféricos de cada cidade, é preciso reconhecer que os qualificadores das comunidades periféricas em um lugar podem não ser os mesmos em outro.

Quase todos os artigos revisados foram produzidos nos Estados Unidos (44), com exceções de Inglaterra (01), Taiwan (01) África do Sul (01) e Brasil (03). Ou seja, apesar de todas as comunidades investigadas serem periferias urbanas em suas cidades, os contextos são provavelmente bem diferentes uns dos outros: uma periferia no Brasil não é a mesma em Taiwan, uma periferia em Brasília não é a mesma no Rio de Janeiro ou em São Paulo. Até mesmo, dentro da mesma cidade, as periferias podem ser diferentes, porque cada lugar possui suas especificidades.

Após estas considerações, poucos artigos se referem a contextos em que a maioria da população escolar é branca (Bodzin, \& Fu, 2013; Bodzin, Fu, Kulo, \& Peffer, 2014; Mulvey, Chiu, Ghosh, \& Bell, 2016). Invariavelmente, os artigos selecionados apresentam a escola periférica como: pobre (Parker, 2014; Dika, \& Amico, 2016; Kane, 2016; Bressler, 2016; Paprzycki, Tuttle, Czerniak, Molitor, Kadervaek, \& Mendenhall, 2017; Ramnarain, 2016; Wyner, \& Doherty, 2017), de maioria negra (Brkich, 2014; Wallace, Perry, Ferguson, \& Jackson, 2014; Berland, \& Wilensky, 2015; Harris, Penuel, Angelo, Debarger, Gallagher, Kennedy, \& Krajcik, 2015; Kane, 2016; Deneroff, 2016; Chapman, \& Feldman, 2016; Ramnarain, 2016; Ball, 2017), latina (Shady, 2014; Aschbacher, Ing, \& Tsai, 2014; Swanson, Bianchini, \& Lee, 2014; Varelas et al., 2014; Carpi, Ronan, Falconer, \& Lents, 2016; González-Howard \& McNeill, 2016; Whitesell, 2016; MoralesDoyle, 2017; Wyner \& Doherty, 2017) e de desempenho escolar baixo (Archer, Dawson, Seakins, \& Wong, 2016).

No Brasil, Soares et al. (2001) foram os únicos autores a fazer a descrição da periferia em seu trabalho de pesquisa. As autoras se concentraram em uma sala de aula comum, sem a necessidade de instalações de laboratório, para alunos de nível médio do Movimento de Educação Popular da Universidade Federal de Uberlândia (UFU). Este movimento é um projeto que atende alunos oriundos de escolas públicas da periferia da cidade de Uberlândia, cujo principal objetivo é rever os tópicos apresentados no ensino médio com uma abordagem de formação do cidadão através do saber.

O que se observou no contexto geral dos artigos é que a escola de periferia é vista principalmente a partir de dois pontos de vista frequentemente hibridizados: o primeiro aborda a periferia como um espaço de carências, onde a maioria dos estudantes pode ser considerada em situação de risco educacional por serem uma população muito pobre, abrigada em uma região densamente povoada, com grande proporção de estudantes não-brancos, taxa de criminalidade acima da média e uma instalação escolar com poucos recursos (Maulucci et al., 2014). Sob outro ponto de vista, a periferia é abordada como espaço, no qual, os potenciais são silenciados. Sob essa lógica, oposta à anterior, os alunos são encorajados a trazer seus conhecimentos para a sala de aula, ao invés de 
confiar apenas na experiência de cientistas ou escritores de livros didáticos. Em aula, são estimulados a expandir seu repertório de raciocínio ao participarem da resolução dos problemas enfrentados pela comunidade (Maulucci et al., 2014).

\section{Resultados e implicações apresentados na literatura}

Por conta da apresentação tipicamente híbrida do discurso educacional, os artigos não teriam sido facilmente classificados em categorias de análise. Optamos, portanto, por classifica-los segundo os resultados empíricos reportados. Dessa forma, para facilitar a compreensão diante dessa diversidade de assuntos abordados na educação científica em periferias, os artigos foram classificados em 11 (onze) temas emergentes segundo o resultado apresentado: (1) ensino e aprendizagem, (2) metodologia eficiente, (3) avaliação, (4) transformação social e democracia, (5) reforma curricular, (6) educação especial e subjetividade, (7) multiculturalismo, (8) gênero, (9) linguagem, (10) identidade científica e (11) aspirações científicas. Após essa classificação, foi confirmada a possibilidade de organizar os temas emergentes em três categorias mais abrangentes (abordagem tradicional, crítica e pós-crítica).

Os temas emergentes a partir dos resultados de pesquisa encontram-se no Quadro 1. Nele, percebemos que 19 (dezenove) artigos foram relacionados a educação tradicional; 07 (sete) artigos foram relacionados à educação crítica enquanto 23 (vinte e três) artigos foram localizados na educação pós-crítica. Essa quantidade de artigos permite antecipar que predomina, na educação científica das periferias, uma preocupação com questões de linguagem, gênero, cor, identidade e aspirações científicas a despeito das relações de classe e dos imperativos de justiça social. Isso talvez resulte da maneira contemporânea como o pensamento norte-americana tem tratado a questão da desigualdade desde o relatório Coleman (Coleman et al., 1966), no qual as diferenças de classe não são realmente consideradas. Examinando rapidamente a ocorrência de artigos, é possível perceber que a educação tradicional das periferias urbanas é recorrente entre os pesquisadores.

Quadro 1. Categorias de análise (continua)

\begin{tabular}{|l|l|l|}
\hline Abordagem & Autores & Tema do Resultado \\
\hline & Brkich, 2014 & $\begin{array}{l}\text { ensino e } \\
\text { aprendizagem }\end{array}$ \\
\cline { 2 - 3 } & $\begin{array}{l}\text { Soares et al., 2001; Bodzin, \& Fu, 2013, Bodzin et al., } \\
\text { 2014; Chen et al., 2014; Duran et al., 2014; Price, Lee, \& }\end{array}$ & \\
Malatesta, 2014; Wallace et al., 2014; Varelas et al., 2014; & $\begin{array}{l}\text { Educação } \\
\text { Tradicional } \\
\text { \& Settlage, 2015; Beckett et al., 2016; Bressler, 2016; } \\
\text { Whitesell, 2016; Wyner, \& Doherty, 2017; Paprzycki et } \\
\text { al., 2017 }\end{array}$ & metodologia eficiente \\
\cline { 2 - 3 } & Dika, \& Amico, 2016; Ramnarain, 2016 & avaliação \\
\hline
\end{tabular}


Quadro 1. Categorias de análise (continuação)

\begin{tabular}{|l|l|l|}
\hline Abordagem & Autores & Tema do Resultado \\
\hline \multirow{5}{*}{ Educação Crítica } & $\begin{array}{l}\text { Maulucci et al., 2014; Shady, 2014; Fellner, 2015; } \\
\text { Schindel Dimick, 2016; Tolbert, \& Bazzul, 2016 }\end{array}$ & $\begin{array}{l}\text { transformação social e } \\
\text { democracia }\end{array}$ \\
\cline { 2 - 3 } & Davis et al, 2014; Morales-Doyle, 2017 & reforma curricular \\
\hline \multirow{5}{*}{$\begin{array}{l}\text { Educação Pós- } \\
\text { Crítica }\end{array}$} & $\begin{array}{l}\text { Hale, 2014; Mulvey et al., 2016 } \\
\text { Paleari, \& Biz, 2010; de Carvalho, 2016; Lowan- } \\
\text { Trudeau, 2016 }\end{array}$ & multicuão especial e \\
\cline { 2 - 3 } & $\begin{array}{l}\text { Parker, 2014; Kwah et al., 2014 } \\
\text { sonzález-Howard, \& McNeill, 2016; Swanson et al, } \\
\text { 2014; Ganhor, 2019 }\end{array}$ & linguagem \\
\cline { 2 - 3 } & $\begin{array}{l}\text { Mclaughlin, 2014; Kane, 2016; Archer et al., 2016; } \\
\text { Chapman, \& Feldman, 2016; Deneroff, 2016; } \\
\text { Guerra, \& Rezende, 2016; Walls, 2016 }\end{array}$ & identidade científica \\
\cline { 2 - 3 } & $\begin{array}{l}\text { Aschbacher, Ing, \& Tsai, 2014; Eisenhart et al., 2015; } \\
\text { Zhang et al., 2016; Carpi et al., 2016; Connors- } \\
\text { Kellgren, Parker, Blustein, \& Barnett, 2016 e Ball, } \\
\text { 2017 }\end{array}$ & aspirações científicas \\
\hline
\end{tabular}

Fonte: Autores (2019).

\section{Educação científica tradicional das periferias urbanas}

O primeiro tema "ensino/aprendizagem" se apoia em um complexo sistema de interações entre alunos e professores onde o "ensino" e a "aprendizagem" são processos independentes, mas interligados. Na visão tradicional, ensinar é transmitir conhecimento e a aprender é adquirir os conhecimentos transmitidos (Kubo, \& Botomé, 2001). Dessa forma, Brkich (2014) reporta a preparação do professor para o uso de analogias capazes de aprofundar a compreensão, entre os alunos, dos conceitos de ciências da terra. $\mathrm{O}$ mesmo artigo argumenta a importância de criticar essas analogias junto com os professores, expandindo suas habilidades didáticas, tornando-os mais eficientes.

Outras pesquisas tratam da metodologia eficiente em seus resultados. Na educação tradicional, é usual que o método de ensino escolhido tenha como propósito otimizar a aquisição de conhecimento e o desenvolvimento de respostas afetivas (atitudes, interesse, motivações) positivas frente à ciência. Nos artigos lidos, há uma preferência pela busca de "programas" como CincySTEM de Beckett et al. (2016) como novo método para alcançar uma "eficiência" na educação científica.

A avaliação, terceiro tema da educação tradicional das periferias urbanas, é um processo que consiste em aferir e analisar as modificações do rendimento 
e comportamento do aluno visando resolver possíveis dificuldades de ensino/ aprendizagem (Sant'Anna, 1995). Nesse sentido, Dika e Amico (2015) apresentam o resultado de uma avaliação feita a estudantes universitários de primeiro ano de diferentes cursos STEM. Concluem que as notam são importantes para que estes alunos retornem para o segundo ano.

\section{Educação científica crítica das periferias urbanas}

Artigos sobre transformação social e democracia tratam da necessidade de uma democratização nas relações existentes nas salas de aula (aluno-professor) para emancipação intelectual do aluno. Para Tolbert e Bazzul (2016), a noção de Rancière (2014) de democracia como exercício do dissenso poderia ser útil para educadores críticos em ciências que desejam dar uma guinada sociopolítica, abordando questões de marginalização, opressão e luta política em primeiro plano.

Enquanto isso, outros artigos tratam da necessidade de uma reforma educacional no currículo de ensino de ciências. Por exemplo, embora seja improvável que os esforços de reforma educacional acabem sozinhos com as adversidades associadas à pobreza, as escolas e as comunidades podem trabalhar em conjunto para ajudar os alunos a lidar com seus contextos sociais de forma a contribuir positivamente para seu desempenho acadêmico. Confiança, respeito e cuidado desempenham papéis importantes no estabelecimento de comunidades de aprendizagem que promovam o desenvolvimento social, emocional e cognitivo nos alunos (Davis et al., 2014).

\section{Educação científica pós-crítica das periferias urbanas}

O primeiro tema da educação pós-crítica diz respeito à subjetividade, trabalhando com o conceito de empatia, ao permitir que os leitores vejam a educação especial do ponto de vista das crianças a quem ela deve servir. Os resultados sugerem que a natureza do desenvolvimento profissional da ciência e da investigação pode aumentar as expectativas dos professores de educação especial de seus alunos com necessidades especiais. Para melhorar os resultados, o desenvolvimento profissional deve aumentar a atenção explícita ao planejamento e estratégias para ajudar a atender às necessidades específicas dos alunos.

Sobre a diversidade multicultural, alguns autores trataram da gestão dos recursos naturais. Lowan-Trudeau (2016) encoraja a exploração da cogestão de recursos naturais por povos indígenas e agências governamentais. A diversidade religiosa do ensino de ciências numa sala com atores advindos de diferentes religiões é encorajada por De Carvalho (2016). Em outra pesquisa, alunos de Botucatu (SP), ao tentar explicar a presença de moradores negros na Ilha de Marajó, levantaram a possibilidade de tal fato ser devido a receberem muito sol, ou serem descendentes de negros ou de índios.

Em relação ao tema gênero e educação científica os autores buscam dar uma atenção ao currículo de ciências em uma escola de meninas, propondo, portanto, uma reflexão quanto à educação científica e gênero. O estudo de Kwah et al. (2014) revela 
como o currículo original pretendido impedia a geração de emoções positivas, focos mútuos de atenção e sentimentos solidariedade de grupo - fatores importantes na geração de interações bem-sucedidas em grupo. Em resposta às emoções expressas por professores e alunos, tomamos esses fatores como um guia para redesenhar o currículo e a implementação do programa, a fim de promover um clima emocional mais positivo e redirecionar as emoções positivas das alunas para o engajamento necessário para alcançar os objetivos.

Quanto à linguagem, González-Howard e McNeill (2016) e Swanson et al., (2014) trabalham com salas de ciências com imersão em inglês para os alunos latinos. Nas duas análises, os autores destacam a necessidade de se trabalhar com grupos pequenos de alunos, pois isso facilitaria o engajamento científico de estudantes que não têm o idioma da escola como primeira língua.

A identidade científica é tema bastante desenvolvido nos estudos em educação científica das periferias. Os autores trabalham com a ideia de construir e consolidar a identidade científica dos estudantes de forma a potencializar a internalização de conceitos de ciências para que suas aspirações científicas ultrapassem a fronteira escolar. Chapman e Feldman (2016) sugerem que a identidade não é apenas socialmente estruturada, mas maleável, pois pode mudar ao longo do tempo e em diferentes contextos. Assim, a identidade em ciências de um indivíduo se desenvolve pela capacidade em fazer ciência (performance), sabendo conteúdos e práticas (competência) científicas, e ser reconhecido como um cientista (reconhecimento). Ser reconhecido como um cientista envolve tanto autoreconhecimento como ser reconhecido por outros, incluindo cientistas e outros profissionais praticantes.

Por último, o estudo de Aschbacher, Ing e Tsai, (2014) mostrou que as percepções e aspirações científicas independiam de gênero e etnia, mas variava de acordo com a situação socioeconômica. Foram encontradas diferenças na popularidade dos campos de carreira STEM, com ciência e medicina sendo mais populares que engenharia e tecnologia, mas a relação positiva básica entre autopercepções científicas e aspirações ocupacionais permaneceram consistentes em todos os campos de carreira. Para os autores, educadores e formuladores de políticas educacionais expressaram preocupação sobre o declínio no interesse dos alunos em se graduarem em profissões relacionadas com a ciência, o que compromete a competitividade da economia, os empregos de classe média e os padrões de consumo pela elite. Ainda, o autor conclui que os alunos perdem esse interesse ao longo da vida, principalmente no ensino médio, onde ciências e matemática parecem ser irrelevantes para suas aspirações pessoais, mesmo possuindo alto interesse pela ciência quando crianças. 


\section{Considerações finais}

Nesta revisão, foram exploradas as contribuições da literatura para o entendimento da educação científica em contexto de periferia urbana. Ao mesmo tempo que esse tema é extensivamente abordado na literatura anglófona desde a década de 1980, no Brasil, observamos que entre os periódicos mais bem avaliados do nosso país, a presença do tema "educação científica das periferias urbanas" é relativamente escassa. Sem diminuir a importância de iniciativas como a do XII Encontro Nacional de Pesquisa em Educação em Ciências (ENPEC), que tinha como tema em 2019, "Pesquisa em Educação em Ciências: Diferença, Justiça Social e Democracia", esse resultado mostra que ainda há muito espaço a ser conquistado!

Os artigos encontrados foram agrupados em categorias (adaptadas da teoria do currículo) que buscam localizar as disputas em torno das quais os pesquisadores se organizam. Percebemos que os debates sobre a educação científica das periferias urbanas giram em torno de temas caros à educação pós-crítica, tais como a linguagem, o gênero, o multiculturalismo, a identidade e as aspirações científicas dos jovens de periferia. A educação tradicional, com sua racionalidade técnica, foca na inovação, otimização e eficiência, é a segunda abordagem mais frequente. As críticas à escassez de recursos nas escolas de periferia, às relações de classe e à falta de justiça social são menos predominantes hoje em dia ainda que esses problemas estejam longe de serem superados - mesmo, ou principalmente, nos Estados Unidos, onde a maior parte da pesquisa é realizada.

O que aprendemos com este trabalho é que esta área de pesquisa pode fornecer novas perspectivas no ensino de ciências, desde nossas práticas na ciência como pesquisadores até as maneiras como reagimos às vidas dos jovens de periferia. O que aprendemostambém temo potencial de enriquecer outros entendimentos, queestruturam a nossa comunidade científica. A ciência deve estar disponível para todos, expandindo suas oportunidades (em vez de restringi-las). Cidadãos da periferia precisam ser vistos como seres de direito, assim como estabelecido em nossa constituição. Porém, para que a periferia receba a atenção devida é preciso documentar, descrever e transformar o cenário do ensino de ciências nas escolas e ambientes comunitários.

\section{Agradecimentos}

Os autores agradecem ao CNPq (processo 436910/2018-7), à FAPDF (processo 00193.00002099/2018-65) e ao Comando da Academia da Polícia Militar do Estado de Goiás pelos incentivos a pesquisa. 


\section{Referências}

Althusser, L. (2013). Ideologias e Aparelhos Ideológicos de Estado. Ed. Contraponto. Apple, M. (1982). Ideologia e currículo. Ed. Brasiliense.

Archer, L., Dawson, E., Seakins, A., \& Wong, B. (2016). Disorientating, fun or meaningful? Disadvantaged families' experiences of a science museum visit. Cultural Studies of Science Education, 11(4), 917-939. https://doi.org/10.1007/s11422-015-9667-7

Aschbacher, P. R., Ing, M., \& Tsai, S. M. (2014). Is Science Me? Exploring Middle School Students' STE-M Career Aspirations. Journal of Science Education and Technology, 23(6), 735-743. https://doi.org/10.1007/s10956-014-9504-x

Ball, C. (2017). Pressurizing the STEM Pipeline: an Expectancy-Value Theory Analysis of Youths ' STEM Attitudes. Journal of Science Education and Technology, 26(4), 372382. https://doi.org/10.1007/s10956-017-9685-1

Barton, A. C. (2002). Urban science education studies: A commitment to equity, social justice and a sense of place. Studies in Sciene Education, 38(1), 37-41.

Bardin, L. (1977). Análise de conteúdo. Edições 70.

Bauman, Z. (2001). Modernidade Líquida. Jorge Zahar.

Beck, U. (2010). Sociedade de risco: Rumo a uma outra modernidade. Tradução de Sebastião Nascimento. Ed. 34. 1986.

Beckett, G. H., Hemmings, A., Maltbie, C., Wright, K., Sherman, M., \& Sersion, B. (2016). Erratum to: Urban High School Student Engagement through CincySTEM iTEST Projects. Journal of Science Education and Technology, 25(6), 1008-1008. https:// doi.org/10.1007/s10956-016-9668-7

Belle, H. B. M. (2011). Escola de Civismo e Cidadania: ethos do Colégio Beta da Polícia Militar de Goiás. Tese. Pontifícia Universidade Católica de Goiás. http://tede2.pucgoias. edu.br:8080/handle/tede/3787

Bernstein, B. A (1996). A estruturação do discurso pedagógico: classe, códigos e controle. Vozes.

Berland, M., \& Wilensky, U. (2015). Comparing Virtual and Physical Robotics Environments for Supporting Complex Systems and Computational Thinking. Journal of Science Education and Technology, 24(5), 628-647 https://doi.org/10.1007/s10956015-9552-x

Bobbitt, J. F. (2004). O currículo. Didática.

Bodzin, A. M., \& Fu, Q. (2013). The Effectiveness of the Geospatial Curriculum Approach on Urban Middle-Level Students' Climate Change Understandings. Journal of Science Education and Technology, 23(4), 575-590. https://doi.org/10.1007/s10956-013-9478-0 
Bodzin, A. M., Fu, Q., Kulo, V., \& Peffer, T. (2014). Examining the Effect of Enactment of a Geospatial Curriculum on Students ' Geospatial Thinking and Reasoning. Journal of Science Education and Technology, 23 (4), 562-574. https://doi.org/10.1007/s10956014-9488-6

Bourdieu, P., \& Passeron, J. C. (1970/2016). A reprodução: elementos para uma teoria do sistema de ensino. Tradução Reynaldo Bairão. Ed. Vozes.

Bressler, D. M. (2016). Investigating Flow Experience and Scientific Practices During a Mobile Serious Educational Game. Journal of Science Education and Technology, 25(5), 795-805. https://doi.org/10.1007/s10956-016-9639-Z

Brkich, K. L. (2013). Urban fifth graders' connections-making between formal earth science content and their lived experiences. Cultural Studies of Science Education, 9(1), 141-164. https://doi.org/10.1007/s11422-013-9505-8

Butler, J. (2003) Problemas de gênero: feminismo e subversão da identidade. Tradução de Renato Aguiar. Civilização Brasileira.

Carpi, A., Ronan, D. M., Falconer, H. M., \& Lents, N. H. (2016). Cultivating Minority Scientists: Undergraduate Research Increases Self-Efficacy and Career Ambitions for Underrepresented Students in STEM. Journal of Research in Science Teaching, 54(2), 169-194. https://doi.org/10.1002/tea.21341

Chapman, A., \& Feldman, A. (2016). Cultivation of science identity through authentic science in an urban high school classroom. Cultural Studies of Science Education, 12(2), 469-491. https://doi.org/10.1007/s11422-015-9723-3

Chen, S., Chang, W., Lai, C., Tsai, C., \& Al, C. E. T. (2014). Education A Comparison of Students ' Approaches to Inquiry, Conceptual Learning, and Attitudes in SimulationBased and Microcomputer-Based Laboratories. Science Education, 98(5), 905-935. https://doi.org/10.1002/sce.21126

Connors-kellgren, A., Parker, C. E., Blustein, D. L., \& Barnett, M. (2016). Innovations and Challenges in Project-Based STEM Education: Lessons from ITEST. Journal of Science Education and Technology, 25(6), 825-832. https://doi.org/10.1007/s10956-016-9658-9

Coleman, J. S., Campbell, E. Q., Hobson, C. J., McPartland, J., Mood, A. M., Weinfeld, F. D., \& York, R. L. (1966). Equality of Educational Opportunity. US Department of Health, Education \& Welfare. Office of Education (OE-38001 and supp.), 548 p.

Davis, N. R., Ingber, J., \& McLaughlin, C. A. (2014). Leveraging complex understandings of urban education for transformative science pedagogy. Cultural Studies of Science Education, 9(4), 925-934. https://doi.org/10.1007/s11422-014-9609-9

De Carvalho, R. (2016). Science initial teacher education and superdiversity: educating science teachers for a multi-religious and globalised science classroom. Cultural Studies of Science Education, 11(2), 253-272. https://doi.org/10.1007/s11422-015-9671-y 
Deleuze, G. (1992). Conversações. (Tradução. Peter Pál Pelbart). Ed. 34.

Derrida, J. (2009). A escritura e a diferença. Perspectiva.

Dika, S. L., \& Amico, M. M. D. (2016). Early Experiences and Integration in the Persistence of First-Generation College Students in STEM and Non-STEM Majors, Journal of Research in Science Teaching, 53(3), 368-383. https://doi.org/10.1002/tea.21301.

Duran, M., Höft, M., Lawson, D. B., Medjahed, B., \& Orady, E. A. (2014). Urban High School Students' IT/STEM Learning: Findings from a Collaborative Inquiry-and Design-Based Afterschool Program. Journal of Science Education and Technology, 23(1), 116-137. https://doi.org/10.1007/s10956-013-9457-5

Eisenhart, M., Weis, L., Allen, C. D., Cipollone, K., \& Stich, A. (2015). High School Opportunities for STEM: Comparing Inclusive STEM-Focused and Comprehensive High Schools in Two US Cities, Journal of Research in Science Teaching. 52(6), 763-769. https://doi.org/10.1002/tea.21213

Fellner, G. (2014). The problem is education not "special education." Cultural Studies of Science Education, 10(4), 1089-1101. https://doi.org/10.1007/s11422-013-9559-7

Freire, P. (2008). Pedagogia do Oprimido. Ed. Paz e Terra.

Foucault, M. (2002) A arqueologia do saber. Trad. Luiz Felipe Baeta Neves. Editora Forense Universitária.

Ganhor, J. P. (2019). O Rap na Educação Científica e Tecnológica Rap. Ciência \& Educação 25(1), 163-180.

Guerra, A., \& Rezende, F. (2016). Sociocultural influences on science and on science identities. Cultural Studies of Science Education, 12(2), 505-511. https://doi.org/10.1007/ s11422-016-9771-3

Giroux, H. (2001) "Praticando estudos culturais nas faculdades de educação". In T. T. da Silva, (Org.). Alienígenas em sala de aula: uma introdução aos estudos culturais em educação. Vozes. pp. 85-103.

González-Howard, M., \& McNeill, K. L. (2016). Learning in a community of practice: Factors impacting english-learning students' engagement in scientific argumentation. Journal of Research in Science Teaching, 53(4), 527-553. https://doi.org/10.1002/tea.21310

Hale, C. (2014). Urban special education policy and the lived experience of stigma in a high school science classroom. Cultural Studies of Science Education. 10(4), 1071-1088. https://doi.org/10.1007/s11422-013-9548-x

Harris, C. J., Penuel, W. R., Angelo, C. M. D., Debarger, A. H., Gallagher, L. P., Kennedy, C. A.,... \& Krajcik, J. S. (2015). Impact of Project-Based Curriculum Materials on Student Learning in Science: Results of a Randomized Controlled Trial, 52(10), 1362 1385. https://doi.org/10.1002/tea.21263 
Kane, J. M. (2016). Young African American Boys Narrating Identities in Science, Journal of Research in Science Teaching, 53(1), 95-118. https://doi.org/10.1002/tea.21247 Kubo, O. M., \& Botomé, S.P. (2001). Uma interação entre dois processos comportamentais. Interação Em Psicologia, 5(1). https://doi.org/http://dx.doi.org/10.5380/psi.v5i1.3321

Kwah, H., Milne, C., Tsai, T., Goldman, R., \& Plass, J. L. (2014). development of an afterschool game design curriculum. Cultural Studies of Science Education, 11(3), 713740. https://doi.org/10.1007/s11422-014-9621-0

Lowan-Trudeau, G. (2016). Gateway to understanding: Indigenous ecological activism and education in urban, rural, and remote contexts. Cultural Studies of Science Education, 12(1), 119-128. https://doi.org/10.1007/s11422-016-9746-4

Maulucci, S. R., Brown, B. A., Grey, S. T., \& Sullivan, S. (2014). Urban Middle School Students ' Reflections on Authentic Science Inquiry. Journal of Research in Science Teaching, 51(9), 1119-1149. https://doi.org/10.1002/tea.21167

McLaughlin, C. A. (2014). Urban science education: examining current issues through a historical lens. Cultural Studies of Science Education, 9(4), 885-923. https://doi. org/10.1007/s11422-014-9598-8

Morales-doyle, D. (2017). Justice-centered science pedagogy: A catalyst for academic achievement and social transformation. Science Education, 101(6), 1034-1060. https:// doi.org/10.1002/sce.21305

Mulvey, B. K., Chiu, J. L., Ghosh, R., \& Bell, R. L. (2016). Special Education Teachers' Nature of Science Instructional Experiences. Journal of Research in Science Teaching, 53(4), 554-578. https://doi.org/10.1002/tea.21311

Paleari, L. M., \& Biz, A. C. (2010). Imagens em Narrativa: contraposição cultural e interdisciplinaridade no ensino fundamental pictures in narrative: cultural counterpoint and interdisciplinarity in Secondary Education. Ciência \& Educação, 16(2), 491-506.

Paprzycki, P., Tuttle, N., Czerniak, C. M., Molitor, S., Kadervaek, J., \& Mendenhall, R. (2017). The Impact of a Framework-Aligned Science Professional Development Program on Literacy and Mathematics Achievement of K-3 Students. Journal of Research in Science Teaching, 54(9), 1174-1196. https://doi.org/10.1002/tea.21400

Parker, C. (2014). Multiple influences: Latinas , middle school science. Cultural Studies of Science Education, 9(2), 317-334. https://doi.org/10.1007/s11422-014-9573-4

Price, C. A., \& Malatesta, H. L. K. (2014). Stereoscopy in Static Scientific Imagery in an Informal Education Setting: Does It Matter? Journal of Science Education and Technology, 23(6), 721-734. https://doi.org/10.1007/s10956-014-9500-1

Rancière, J. (2005/2014). O ódio à democracia. 1. Ed. Boitempo. 
Ramnarain, U. (2016). Understanding the Influence of Intrinsic and Extrinsic Factors on Inquiry-Based Science Education at Township Schools in South Africa. Journal of Research in Science Teaching, 53(4), 598-619. https://doi.org/10.1002/tea.21315

Sant'Anna, I. M. Por que avaliar?: como avaliar?: critérios e instrumentos. 12. Ed. Vozes, 1995.

Schindel Dimick, A. (2016). Exploring the Potential and Complexity of a Critical Pedagogy of Place in Urban Science Education. Science Education, 100(5), 814-836. https://doi.org/10.1002/sce.21233

Silva, T. T. (1999). Documentos de Identidade: uma introdução às teorias de currículo. Autênctica Editora LTDA.

Shady, A. (2013). Negotiating cultural differences in urban science education: an overview of teacher's first-hand experience reflection of cogen journey. Cultural Studies of Science Education, 9(1), 31-51. https://doi.org/10.1007/s11422-013-9486-7

Soares, M. H. F., Silva, M. V. B., \& Cavalheiro, E. T. G. (2001). Aplicação de corantes naturais no ensino médio. Eclética Química, 26 (1), 225-234. https://dx.doi.org/10.1590/ S0100-46702001000100017

Stuckey, M., Hofstein, A., Mamlok-Naaman, R., \& Eilks, I. (2013). The meaning of "relevance" in science education and its implications for the science curriculum. Studies in Science Education, 49(1), 1-34. https://doi.org/10.1080/03057267.2013.802463

Swanson, L. H., Bianchini, J. A., \& Lee, J. S. (2014). Engaging in argument and communicating information: A case study of english language learners and their science teacher in an urban high school. Journal of Research in Science Teaching, 51(1), 31-64. https://doi.org/10.1002/tea.21124

Tyler, R. (1983). Princípios Básicos de currículo e ensino, Porto Alegre: Ed. Globo.

Tolbert, S., \& Bazzul, J. (2016). Toward the sociopolitical in science education. Cultural Studies of Science Education, 12(2), 321-330. https://doi.org/10.1007/s11422-016-9737-5

Varelas, M., Pieper, L., Arsenault, A., \& Pappas, C. C. (2014). How Science Texts and Hands-On Explorations Facilitate Meaning Making: Learning From Latina / o Third Graders. Journal of Research in Science Teaching, 51(10), 1246-1274. https://doi. org/10.1002/tea.21173

Wallace, E. W., Perry, J. C., Ferguson, R. L., \& Jackson, D. K. (2014). The Careers in Health and Medical Professions Program ( CHAMPS ): An Impact Study of a University-Based STEM + H Outreach Program. Journal of Science Education and Technology, 24(4), 484495. https://doi.org/10.1007/s10956-014-9536-2

Walls, L. (2016). Equitable research: a bridge too far? Cultural Studies of Science Education, 12(2), 493-503. https://doi.org/10.1007/s11422-016-9770-4 
Wenner, J. A., \& Settlage, J. (2015). School Leader Enactments of the Structure / Agency Dialectic Via Buffering. Journal of Research in Science Teaching, 52(4), 503-515. https:// doi.org/10.1002/tea.21212

Whitesell, E. R. (2016). Research Article A Day at the Museum: The Impact of Field Trips on Middle School Science Achievement. Journal of Research in Science Teaching, 53(7), 1036-1054. https://doi.org/10.1002/tea.21322

Wyner, Y., \& Doherty, J. H. (2017). Developing a learning progression for threedimensional learning of the patterns of evolution. Science Education, 101(5), 787-817. https://doi.org/10.1002/sce.21289

Zhang, L., Barnett, M., Wassell, B., Kate, Æ. S., Tan, E., Calabrese, Æ. A., ... Maulucci, M. S. R. (2016). Leveraging complex understandings of urban education for transformative science pedagogy. Cultural Studies of Science Education, 6(2), 469-491. https://doi. org/10.1007/s11422-013-9546-Z

Sullyvan Garcia-Silva

https://orcid.org/0000-0002-9843-5672 Polícia Militar do Estado de Goiás Programa de Pós-Graduação em Polícia e Segurança Pública Goiânia, Goiás, Brasil sull.garcia@pm.go.gov.br

Paulo Lima Junior https://orcid.org/0000-0002-3382-8387 Universidade de Brasília Instituto de Física Brasília, Distrito Federal, Brasil paulolimajr@unb.br

Submetido em 11 de dezembro de 2019 Aceito em $\mathbf{3 0}$ de março de $\mathbf{2 0 2 0}$ Publicado em 22 de abril de 2020 